УДК 338:330.131.7-044.3(470)

DOI dx.doi.org/10.24866/1813-3274/2019-4/30-52

Н. В. Кузнецова ${ }^{1}$, Дальневосточный федеральный университет, Владивосток, Россия

E-mail: kuznetsova.nv@dvfu.ru

Е. В. Кочева ${ }^{2}$, Дальневосточный федеральный университет,

Владивосток, Россия

E-mail: kocheva.ev@dvfu.ru

Н. А. Матев ${ }^{3}$, Дальневосточный федеральный университет,

Владивосток, Россия

E-mail: matev.na@dvfu.ru

\title{
МЕТОДИКА ОЦЕНКИ СОЦИАЛЬНО-ЭКОНОМИЧЕСКИХ РИСКОВ ДЛЯ ОТВЕТА РОССИИ НА БОЛЬШИЕ ВЫЗОВЫ“
}

Аннотащия. Проблема нового качества развития российской экономики, с точки зрения достижения стратегических целей развития и сокращения разрыва с развитыми странами, обсуждается уже много лет. Особую актуальность проблемы управления развитием больших социально-экономических систем приобретают в условиях парадигмы «больших вызовов», что требует их теоретического осмысления. «Большие вызовы» могут быть классифицированы по многим группам факторов: экономические и структурные вызовы, социальные вызовы, экологические и природно-

\footnotetext{
${ }^{1}$ Наталия Викторовна Кузнецова, доктор экономических наук, профессор, профессор кафедры мировой экономики, Школа экономики и менеджмента, Дальневосточный федеральный университет, г. Владивосток, Россия.

${ }^{2}$ Екатерина Викторовна Кочева, кандидат экономических наук, доцент кафедры бизнес-информатики и экономико-математических методов, Школа экономики и менеджмента, Дальневосточный федеральный университет, г. Владивосток, Россия.

${ }^{3}$ Николай Анатольевич Матев, кандидат экономических наук, доцент кафедры бизнес-информатики и экономико-математических методов, Школа экономики и менеджмента, Дальневосточный федеральный университет, г. Владивосток, Россия.

* Результаты были получены при выполнении научного проекта Российского фонда фундаментальных исследований (РФФИ) № 18-014-00001 «Модель мультивекторной социально-экономической политики взаимодействия российского Дальнего Востока и стран АТР - пути снижения неожиданных эффектов от наступления «больших вызовов».

Для цитирования: Кузнецова Н. В., Кочева Е. В., Матев Н. А. Методика оценки социальноэкономических рисков для ответа России на большие вызовы // Азиатско-Тихоокеанский регион: экономика, политика и право. 2019. № 4. С. 29-52.
}

(C) Кузнецова Н. В., Кочева Е. В., Матев Н. А., 2019 
ресурсные вызовы, ценностные вызовы, технологические вызовы, политические и институциональные вызовы и др. В разных странах меняются приоритеты этих вызовов, в зависимости от уровня их развития. Концепция настоящего исследования «больших вызовов» исходит из посыла, что в процессе глобализации экономических отношений происходит формирование качественно новой модифицированной хозяйственной системы любой страны, присущей внутренней среде национальных хозяйственных систем. Они создают причины угроз всей мировой экономике, создают барьеры и разрывы, которые обусловливают сегментацию мировой экономической системы. Главной фундаментальной научной задачей, на решение которой будет направлено исследование, - готовность России к существующими возникающим «большим вызовам», определение путей уменьшения риска и возможностей возникновения негативных событий, определение инфраструктурных и пространственных целей развития субъектов РФ, исходя из существующих рисков. В нашей работе идёт речь о необходимости системного исследования смены приоритетных направлений развития под угрозой неожиданных эффектов больших вызовов. Основной целью данного этапа исследования является определение и оценка уровня социальноэкономических рисков для ответа России на «большие вызовы» и проведение классификации субъектов Российской Федерации по рассчитанным интегральным показателям, характеризующим уровень социально-экономических рисков. Также отдельно рассмотрены приоритетные направления развития субъектов Дальнего Востока в контексте выделенных больших вызовов.

Ключевые слова: большие вызовы, социально-экономические риски, интегральный показатель, национальные интересы, конкурентоспособность, методика, оценка, концепция, технологический разрыв, инновации, сырьевая отсталость, экспортно-сырьевая модель, инвестиции, человеческий потенциал, качество жизни, рынок труда, экономический рост, стратегия, внешнеэкономическая деятельность. 
Natalia V. Kuznetsova ${ }^{1}$, Far Eastern Federal University, Vladivostok, Russia E-mail: kuznetsova.nv@dvfu.ru

Ekaterina V. Kocheva ${ }^{2}$, Far Eastern Federal University, Vladivostok, Russia E-mail: kuznetsova.nv@dvfu.ru

Nikolay A. Matev ${ }^{3}$ Far Eastern Federal University, Vladivostok, Russia

E-mail: matev.na@dvfu.ru

\section{METHODOLOGY OF ASSESSING THE SOCIAL AND ECONOMIC RISKS FOR RUSSIA'S RESPONSE TO BIG CHALLENGES*}

Abstract. The problem of new quality economic development of Russia has been discussed for many years in the context of strategic development goals and shortening the gap with advanced countries. Managing the development of big social-economic systems has become relevant in the context of big challenges that call for theoretical grounds. "Big challenges" can be classified by many factor groups: economic and structural challenges, social challenges, ecological and resource-related challenges, value challenges, technological challenges, political and institutional challenges, etc. Different countries have different priorities for these challenges depending of their development levels. The concept of the present research is based on the idea that globalization of economic relations forms a qualitatively new, modified economic system of any country, inherent to the internal environment of national economic systems. They create threats to the whole global economy and create barriers and gaps that lead to the segmentation of the global economic system. The main fundamental research goal of this task is to research the readiness of Russia for emerging "big challenges", finding the ways of decreasing the risks and negative consequences, defining the infrastructural and territorial goals of developing

\footnotetext{
${ }^{1}$ Natalia V. Kuznetsova, Doctor of Economics, Professor, International Economics Department, School of Economics and Management, Far Eastern Federal University, Vladivostok, Russia.

${ }^{2}$ Ekaterina V. Kocheva, Candidate of Economic Sciences, Associate Professor, Department of Business Informatics, Economic and Mathematical Methods, School of Economics and Management, Far Eastern Federal University, Vladivostok, Russia.

${ }^{3}$ Nikolay A. Matev, Candidate of Economic Sciences, Associate Professor, Department of Business Informatics, Economic and Mathematical Methods, School of Economics and Management, Far Eastern Federal University, Vladivostok, Russia.

For citing: Kuznetsova N.V., Kocheva E.V., Matev N.A. Methodology of assessing the social and economic risks for Russia's response to big challenges // PACIFIC RIM: Economics, Politics, Law. 2019. No 4. P. 30-52.

* The results were obtained in the process of fulfilling the research project of the Russian Foundation for Basic Research (RFBR) \# 18-014-00001 «Model of the multi-vector social and economic policy of the Russian Far East and Pacific Rim countries - the ways of reducing the unexpected effects caused by "big challenges".
} 
the RF subjects based on the existing risks. Our research shows the need for systemic research of the changing priority development trends threatened by unexpected big challenges. This stage of our research is mainly targeted at defining and assessing the level of social and economic risks for Russia's response to "big challenges" and classifying the $\mathrm{RF}$ subjects in accordance with calculated integral indicators that characterize the level of social and economic risks. The priority development trends of the RFE subjects have been also reviewed in the context of big challenges.

Key words: big challenges, social and economic risks, integral indicators, national interests, competitiveness, methods, assessment, concept, technological gap, innovations, underdevelopment of resource base, export-resource model, investment, HR potential, life quality, labor market, economic growth, strategy, foreign economic activity.

В настоящее время стратегия развития Российской Федерации основывается на принципах обеспечения национальных интересов. В связи с этим, особую актуальность приобретают вопросы нового вектора социально-экономического развития страны в условиях имеющихся больших вызовов.

Исследования «больших вызовов» в большей степени построены на констатации проблемных зон в мировом пространстве, например, изменение климата - ГовардГренвил [1], Дж. Джордж, Дж. Говард-Гренвиль [2, с. 615-623]; старение общества К. Кулик, С. Райан, С. Харпер и Дж. Джордж [3, с. 929-935]; природные ресурсы Дж. Джордж, С. Счиллебекх и Т. Лиак [4, с. 1595-1613]. Концепция «больших вызовов», по мнению П. Холла, скорее «нормальная разработка политики» [5]. Дж. Ван дер Вегт, П. Эссенс, М. Вольстром и Дж. Джордж считают, что большие вызовы могут нарушить социальную устойчивость [6, с. 971-980]. С. Гродал и С. Махоуни считают, что «большие вызовы» - это сложные проблемы, имеющие далеко идущие социальные последствия и не имеющие чёткого решения [7, 1801]. А. Колберт, Н. Йее и Дж. Джордж [8, с. 731-739] видят «цифровую рабочую силу» фактором для появления больших вызовов, М. Доджсон, Д. Ганн, И. Владвски-Бергер, Н. Султан и Дж. Джордж [9, с. 325-333] видят цифровые деньги причиной для распространения больших вызовов. А. Джоши, Б. Нили, К. Эмрих, К. Гриффитс и Дж. Джордж [10, с. 1459-1475] отмечают влияние гендерного неравенства на причины возникновения больших вызовов. Ч. В. Черчман [11, с. 141-142], Г. Риттел и М. Веббер [12, с. 155-169] придерживаются мнения, что большие вызовы - это амбициозные проблемы, которые не имеют чёткого единого решения и охватывают неполные, противоречивые или изменяющиеся требования, которые часто разворачиваются в сложных системах. В. В. Клочков, С. М. Рождественская справедливо отмечают, что масштабные глобальные проблемы, требующие качественного прорыва, вряд ли могут быть преодолены в одиночку, в режиме автаркии [13]. Исследователи организации «Grand Challenges Canada» [14] пишут, что большие вызовы необходимо рассматривать в качестве конкретного критического барьера, который, если его удалить, поможет решить важную социальную проблему с 
высокой вероятностью глобального воздействия путём широкого внедрения. Это видение базируется на трёх основных принципах: научное совершенство; конкурентное сотрудничество; ответственность за результаты. В своих предыдущих исследованиях мы также определяли имеющиеся угрозы и большие вызовы России [15]. Большие вызовы - объективно требующая реакции со стороны государства совокупность проблем, угроз и возможностей, сложность и масштаб которых таковы, что они не могут быть решены, устранены или реализованы исключительно за счёт увеличения ресурсов [16].

В свою очередь, большие вызовы создают определённые риски для государства и общества и одновременно являются причиной для возникновения новых перспектив научно-технологического развития страны.

Определение социально-экономических рисков предполагает формирование набора показателей, с помощью которого представляется возможным производить мониторинг и оценку выделенных рисков, а также на их основе классифицировать субъекты Российской Федерации (табл. 1).

Таблицуа 1

\section{Набор показателей для оценки социально-экономических рисков}

\begin{tabular}{|c|c|c|}
\hline Вызовы & Риски & Показатели \\
\hline $\begin{array}{l}\text { Новая волна техноло- } \\
\text { гических изменений. } \\
\text { Подъём конкуренто- } \\
\text { способности страны на } \\
\text { мировых высокотех- } \\
\text { нологичных рынках }\end{array}$ & $\begin{array}{l}\text { РИСК снижения } \\
\text { конкуренто- } \\
\text { способности }-R_{l}\end{array}$ & $\begin{array}{l}\text { 1. Объём промышленного производства } \\
\text { на душу населения, тыс. рублей - INPR } \\
\text { 2. Объём выпущенной продукции организа- } \\
\text { ций с участием иностранного капитала, } \\
\text { на душу населения, млрд рублей - VO } \\
\text { 3. Удельный вес убыточных организаций, } \\
\text { в процентах - UE } \\
\text { 4. Степень износа основных фондов, } \\
\text { в процентах - DFA } \\
\text { 5. Удельный вес организаций, осуществля- } \\
\text { ющих технологические инновации, } \\
\text { в процентах - TIO }\end{array}$ \\
\hline $\begin{array}{l}\text { Преодоление консер- } \\
\text { вативности внешне- } \\
\text { экономической дея- } \\
\text { тельности. } \\
\text { Необходимость } \\
\text { догнать страны лидеры } \\
\text { по продвижению } \\
\text { продукции на мировые } \\
\text { рынки }\end{array}$ & $\begin{array}{l}\text { РИСК потери по- } \\
\text { тенциала взаим- } \\
\text { ных торговых по- } \\
\text { токов и дальней- } \\
\text { шей интеграции в } \\
\text { отраслевые товар- } \\
\text { ные рынки - } R_{2}\end{array}$ & $\begin{array}{l}\text { 1. Объём экспорта на душу населения, } \\
\text { тыс. долл. США - EX } \\
\text { 2. Объём импорта на душу населения, } \\
\text { тыс. долл. США - IM } \\
\text { 3. Внешнеторговый оборот на душу - FTT } \\
\text { 4. Торговый баланс- TB }\end{array}$ \\
\hline
\end{tabular}


Кузнецова Н. В., Кочева Е. В., Матев Н. А. Методика оценки социально-экономических рисков для ответа России на большие вызовы

Продолжение табл. 1

\begin{tabular}{|c|c|c|}
\hline $\begin{array}{l}\text { Необходимость } \\
\text { преодоления техно- } \\
\text { логического разрыва }\end{array}$ & $\begin{array}{l}\text { РИСК отставания } \\
\text { научно-техничес- } \\
\text { кого потенциала } \\
\text { и снижения инно- } \\
\text { вационной актив- } \\
\text { ности экономики - } \\
R_{3}\end{array}$ & $\begin{array}{l}\text { 1. Доля организаций, выполняющих НИР, } \\
\text { в общем количестве, в процентах - OPSR } \\
\text { 2. Затраты на НИР на душу населения, } \\
\text { тыс. рублей - RC } \\
\text { 3. Затраты на технологические инновации } \\
\text { на душу населения, тыс. рублей - TI } \\
\text { 4. Объём инновационных товаров, работ, } \\
\text { услуг в общем объёме, в процентах - VIP } \\
\text { 5. Количество выданных патентов } \\
\text { на } 1 \text { млн человек населения - PAT } \\
\text { 6. Доля персонала, занятого НИР, в общей } \\
\text { численности занятых, в процентах - PRD } \\
\text { 7. Численность исследователей с учёными } \\
\text { степенями на } 10 \text { 000 чел. населения - RES } \\
\text { 8. Численность студентов, обучающихся } \\
\text { по программам бакалавриата, специалите- } \\
\text { та, магистратуры, на } 10000 \text { чел. - STUD } \\
\text { 9. Число передовых производственных } \\
\text { технологий, на } 1 \text { млн чел. - NAT }\end{array}$ \\
\hline \multirow[t]{2}{*}{$\begin{array}{l}\text { Исчерпание потенци- } \\
\text { ала экспортно- } \\
\text { сырьевой модели } \\
\text { экономического } \\
\text { развития России }\end{array}$} & $\begin{array}{l}\text { РИСК сырьевой } \\
\text { отсталости }-R_{4}\end{array}$ & $\begin{array}{l}\text { 1. Индекс производства в сфере добычи } \\
\text { полезных ископаемых - IGVA } \\
\text { 2. Доля ВДС добывающих производств } \\
\text { в общем объёме - GVA } \\
\text { 3. Доля отгруженных товаров добывающих } \\
\text { производств в общем объёме - } M G \\
\text { 4. Доля работников добывающих произ- } \\
\text { водств в общей численности занятых - } \\
M I W\end{array}$ \\
\hline & $\begin{array}{l}\text { РИСК сужения } \\
\text { производства то- } \\
\text { варов массового } \\
\text { потребления, в } \\
\text { первую очередь } \\
\text { продовольствия - } \\
R_{5}\end{array}$ & $\begin{array}{l}\text { 1. Объёмы реализации пищевых продуктов } \\
\text { организациями торговли и общественного } \\
\text { питания - FS } \\
\text { 2. Доля расходов на продовольствие } \\
\text { в общих расходах населения - FE } \\
\text { 3. Индекс потребительских цен на пище- } \\
\text { вые продукты - CPI }\end{array}$ \\
\hline $\begin{array}{l}\text { Развитие макротех- } \\
\text { нологических } \\
\text { производств }\end{array}$ & $\begin{array}{l}\text { РИСК снижения } \\
\text { инвестиционной } \\
\text { привлекатель- } \\
\text { ности }-R_{6}\end{array}$ & $\begin{array}{l}\text { 1. Инвестиции в основной капитал } \\
\text { на душу населения - FI } \\
\text { 2. Поступление прямых иностранных инве- } \\
\text { стиций в расчёте на душу населения - FII } \\
\text { 3. Индекс физического объёма инвести- } \\
\text { ций - PII }\end{array}$ \\
\hline
\end{tabular}


Окончание табл. 1

\begin{tabular}{|c|c|c|}
\hline Вызовы & Риски & Показатели \\
\hline \multirow[t]{7}{*}{$\begin{array}{l}\text { Формирование каче- } \\
\text { ственного экономи- } \\
\text { ческого роста }\end{array}$} & $\begin{array}{l}\text { РИСК деградации } \\
\text { человеческого } \\
\text { потенциала }-R_{7} \text { : }\end{array}$ & \\
\hline & $\begin{array}{l}\text { 1. Сокращение } \\
\text { численности } \\
\text { населения }\end{array}$ & $\begin{array}{l}\text { 1. Общий коэффициент рождаемости - } C B \\
\text { 2. Общий коэффициент смертности - } C M \\
\text { 3. Коэффициент младенческой смертно- } \\
\text { сти - CIM } \\
\text { 4. Коэффициент миграционного прироста - } \\
\text { MI }\end{array}$ \\
\hline & $\begin{array}{l}\text { 2. Социальное } \\
\text { расслоение } \\
\text { общества }\end{array}$ & $\begin{array}{l}\text { 1. Уровень бедности }-P L \\
\text { 2. Коэффициент фондов }-C D \\
\text { 3. Коэффициент Джини }-G F\end{array}$ \\
\hline & $\begin{array}{l}\text { 3. Социально зна- } \\
\text { чимые заболева- } \\
\text { ния }\end{array}$ & $\begin{array}{l}\text { 1. Новообразования }-N D \\
\text { 2. Туберкулёз - TUB } \\
\text { 3. ВИч/СПИД - AIDS } \\
\text { 4. Наркомания }-D A \\
\end{array}$ \\
\hline & $\begin{array}{l}\text { РИСК снижения } \\
\text { качества жизни } \\
\text { населения }-R_{8}\end{array}$ & $\begin{array}{l}\text { 1. Реальные денежные доходы населения - } \\
R C I \\
\text { 2. Реальный размер назначенных пенсий - } R P \\
\text { 3. Общая площадь жилых помещений, } \\
\text { приходящихся в среднем на одного жите- } \\
\text { ля,- } L S \\
\text { 4. Мощность амбулаторно- } \\
\text { поликлинических организаций - } A C L \\
\text { 5. Нагрузка на работников сферы здраво- } \\
\text { охранения - AC }\end{array}$ \\
\hline & $\begin{array}{l}\text { РИСК напряжён- } \\
\text { ности на рынке } \\
\text { труда }-R_{9}\end{array}$ & $\begin{array}{l}\text { 1. Уровень безработицы - UN } \\
\text { 2. Коэффициент напряжённости - CT } \\
\text { 3. Среднее время поиска работы }-J S T\end{array}$ \\
\hline & $\begin{array}{l}\text { РИСК загрязнения } \\
\text { окружающей сре- } \\
\text { ды }-R_{10}\end{array}$ & $\begin{array}{l}\text { 1. Выбросы загрязняющих веществ в атмо- } \\
\text { сферный воздух - } A E \\
\text { 2. Сброс загрязнённых сточных вод в по- } \\
\text { верхностные водные объекты - } W W \\
\text { 3. Доля уловленных и обезвреженных за- } \\
\text { грязняющих атмосферу веществ в общем } \\
\text { количестве отходящих загрязняющих } \\
\text { веществ от стационарных источников-- } \\
T S A\end{array}$ \\
\hline
\end{tabular}


Кузнецова Н. В., Кочева Е. В., Матев Н. А. Методика оценки социально-экономических рисков для ответа России на большие вызовы

В настоящем исследовании для комплексности анализа социальноэкономических рисков в каждом из выделенных блоков предполагается рассчитать интегральную характеристику.

На первом этапе построения интегральной характеристики для оценки рисков $\left(R_{i}\right)$ была сформирована информационная база статистических показателей (табл. 1).

На втором этапе происходит приведение выделенных показателей к сопоставимому виду. Для процедуры нормировки исходного набора индикаторов будут использоваться линейные преобразования видов (формулы 1,2$)$.

$$
\widehat{x_{i}}=\frac{x_{i}-x_{\min }}{x_{\max }-x_{\min }} \quad \text { 1) } \widehat{x}_{\mathrm{i}}=\frac{x_{\max }-x_{i}}{x_{\max }-x_{\min }}
$$

где $x_{i}$ - фактическое значение нормируемого показателя;

$x_{\max }$ - максимальное значение нормируемого показателя;

$x_{\min }$ - минимальное значение нормируемого показателя.

Если большее значение нормируемого показателя соответствует более низкому риску, то нормировку следует проводить по формуле (1), в обратном случае по формуле (2). В результате применения данной процедуры все вышеобозначенные индикаторы будут приведены к единой шкале от 0 до 1 . Чем ближе значение нормированного индикатора к верхней границе указанного диапазона, тем ниже риски. Определение референтных точек основывалось на имеющихся эмпирических данных по всем субъектам Российской Федерации за анализируемый период времени (2010-2017 гг.).

Далее по каждому выделенному блоку показателей рассчитывается интегральный индикатор (формула 3):

$$
R_{i}=\sum_{i=1}^{n} \alpha_{i} \widehat{x}_{i}
$$

где $R_{i}-$ интегральный показатель для $i$-го риска;

$\widehat{\mathrm{x}_{1}}-$ значения нормированных индикаторов в соответствующем блоке;

$\alpha_{i}-$ весовые коэффициенты для соответствующих индикаторов.

Весовые коэффициенты для соответствующих индикаторов определяются по следующей схеме:

1. В каждом из представленных десяти рисков рассчитываются корреляционные матрицы взаимосвязи входящих в блок индикаторов. 
2. Для каждого индикатора производится суммирование корреляционных коэффициентов, характеризующих его взаимосвязи с остальными индикаторами блока $\left(r_{j}\right)$.

3. Рассчитывается сумма всех коэффициентов корреляции в матрице $\left(r_{i j}\right)$.

4. Определяется весовой коэффициент $\left(\alpha_{i}\right)$ для соответствующего индикатора как частное от деления $r_{j}$ на $r_{i j}$.

Интегральные показатели социально-экономических рисков будут находиться в диапазоне от 0 до 1, причём более высокие значения интегральной характеристики будут свидетельствовать о низкой степени социально-экономических рисков. Качественная оценка интегральных показателей приведена в табл. 2.

Таблица 2

\section{Характеристика значений интегральных показателей}

социально-экономических рисков для России

\begin{tabular}{|l|l|}
\hline \multicolumn{1}{|c|}{ Значение показателя } & \multicolumn{1}{|c|}{ Характеристика } \\
\hline $0,000-0,399$ & Критический риск \\
\hline $0,400-0,499$ & Высокий риск \\
\hline $0,500-0,599$ & Допустимый риск \\
\hline $0,600-0,699$ & Умеренный риск \\
\hline $0,700-0,799$ & Низкий риск \\
\hline $0,800-1,000$ & Очень низкий риск \\
\hline
\end{tabular}

Предложенная методика была апробирована по данным субъектов Российской Федерации за период 2010-2017 гг. Итоги расчётов на конец исследуемого периода представлены в табл. 3.

Таблицуа 3

Значения интегральных показателей социально-экономических рисков в субъектах России в 2017 г.

\begin{tabular}{|l|c|c|c|c|c|c|c|c|c|c|}
\hline \multicolumn{1}{|c|}{ Субъект } & $R_{1}$ & $R_{2}$ & $R_{3}$ & $R_{4}$ & $R_{5}$ & $R_{6}$ & $R_{7}$ & $R_{8}$ & $R_{9}$ & $R_{10}$ \\
\hline $\begin{array}{l}\text { Белгородская } \\
\text { область }\end{array}$ & 0,746 & 0,631 & 0,606 & 0,737 & 0,634 & 0,547 & 0,699 & 0,762 & 0,740 & 0,585 \\
\hline $\begin{array}{l}\text { Брянская } \\
\text { область }\end{array}$ & 0,662 & 0,511 & 0,497 & 0,099 & 0,492 & 0,326 & 0,545 & 0,544 & 0,565 & 0,627 \\
\hline $\begin{array}{l}\text { Владимирская } \\
\text { область }\end{array}$ & 0,696 & 0,577 & 0,621 & 0,348 & 0,681 & 0,509 & 0,548 & 0,511 & 0,666 & 0,493 \\
\hline $\begin{array}{l}\text { Воронежская } \\
\text { область }\end{array}$ & 0,744 & 0,558 & 0,680 & 0,379 & 0,710 & 0,534 & 0,681 & 0,590 & 0,656 & 0,601 \\
\hline $\begin{array}{l}\text { Ивановская } \\
\text { область }\end{array}$ & 0,547 & 0,501 & 0,465 & 0,215 & 0,691 & 0,412 & 0,534 & 0,569 & 0,607 & 0,537 \\
\hline $\begin{array}{l}\text { Калужская } \\
\text { область }\end{array}$ & 0,719 & 0,684 & 0,721 & 0,334 & 0,619 & 0,568 & 0,673 & 0,408 & 0,686 & 0,616 \\
\hline
\end{tabular}


Кузнецова Н. В., Кочева Е. В., Матев Н. А. Методика оценки социально-экономических рисков для ответа России на большие вызовы

Продолжение табл. 3

\begin{tabular}{|c|c|c|c|c|c|c|c|c|c|c|}
\hline $\begin{array}{l}\text { Костромская } \\
\text { область }\end{array}$ & 0,605 & 0,512 & 0,360 & 0,162 & 0,715 & 0,424 & 0,658 & 0,534 & 0,669 & 0,501 \\
\hline Курская область & 0,659 & 0,546 & 0,589 & 0,700 & 0,678 & 0,477 & 0,681 & 0,606 & 0,572 & 0,671 \\
\hline $\begin{array}{l}\text { Липецкая } \\
\text { область }\end{array}$ & 0,729 & 0,677 & 0,464 & 0,387 & 0,659 & 0,633 & 0,684 & 0,569 & 0,699 & 0,488 \\
\hline $\begin{array}{l}\text { Московская } \\
\text { область }\end{array}$ & 0,712 & 0,616 & 0,739 & 0,302 & 0,558 & 0,591 & 0,681 & 0,756 & 0,715 & 0,572 \\
\hline $\begin{array}{l}\text { Орловская } \\
\text { область }\end{array}$ & 0,642 & 0,507 & 0,530 & 0,058 & 0,625 & 0,423 & 0,672 & 0,592 & 0,548 & 0,535 \\
\hline $\begin{array}{l}\text { Рязанская } \\
\text { область }\end{array}$ & 0,682 & 0,586 & 0,587 & 0,283 & 0,566 & 0,521 & 0,672 & 0,537 & 0,605 & 0,557 \\
\hline $\begin{array}{l}\text { Смоленская } \\
\text { область }\end{array}$ & 0,651 & 0,617 & 0,510 & 0,292 & 0,574 & 0,486 & 0,546 & 0,605 & 0,550 & 0,558 \\
\hline $\begin{array}{l}\text { Тамбовская } \\
\text { область }\end{array}$ & 0,660 & 0,470 & 0,524 & 0,050 & 0,734 & 0,471 & 0,673 & 0,503 & 0,610 & 0,499 \\
\hline $\begin{array}{l}\text { Тверская } \\
\text { область }\end{array}$ & 0,650 & 0,501 & 0,610 & 0,207 & 0,633 & 0,484 & 0,545 & 0,599 & 0,647 & 0,545 \\
\hline $\begin{array}{l}\text { Тульская } \\
\text { область }\end{array}$ & 0,693 & 0,642 & 0,537 & 0,364 & 0,634 & 0,569 & 0,669 & 0,504 & 0,682 & 0,526 \\
\hline $\begin{array}{l}\text { Ярославская } \\
\text { область }\end{array}$ & 0,655 & 0,567 & 0,701 & 0,209 & 0,704 & 0,497 & 0,679 & 0,552 & 0,538 & 0,490 \\
\hline г. Москва & 0,759 & 0,841 & 0,820 & 0,468 & 0,647 & 0,698 & 0,828 & 0,795 & 0,954 & 0,675 \\
\hline $\begin{array}{l}\text { Республика } \\
\text { Карелия }\end{array}$ & 0,551 & 0,607 & 0,516 & 0,752 & 0,651 & 0,530 & 0,665 & 0,563 & 0,501 & 0,379 \\
\hline $\begin{array}{l}\text { Республика } \\
\text { Коми }\end{array}$ & 0,584 & 0,556 & 0,525 & 0,867 & 0,638 & 0,514 & 0,688 & 0,417 & 0,584 & 0,341 \\
\hline $\begin{array}{l}\text { Архангельская } \\
\text { область }\end{array}$ & 0,653 & 0,592 & 0,559 & 0,806 & 0,733 & 0,681 & 0,668 & 0,562 & 0,560 & 0,401 \\
\hline $\begin{array}{l}\text { Вологодская } \\
\text { область }\end{array}$ & 0,672 & 0,637 & 0,407 & 0,130 & 0,672 & 0,630 & 0,672 & 0,429 & 0,572 & 0,435 \\
\hline $\begin{array}{l}\text { Калининград- } \\
\text { ская область }\end{array}$ & 0,632 & 0,706 & 0,421 & 0,520 & 0,576 & 0,604 & 0,675 & 0,589 & 0,622 & 0,554 \\
\hline $\begin{array}{l}\text { Ленинградская } \\
\text { область }\end{array}$ & 0,713 & 0,688 & 0,517 & 0,429 & 0,679 & 0,706 & 0,667 & 0,755 & 0,713 & 0,482 \\
\hline $\begin{array}{l}\text { Мурманская } \\
\text { область }\end{array}$ & 0,649 & 0,663 & 0,508 & 0,768 & 0,656 & 0,641 & 0,674 & 0,493 & 0,579 & 0,376 \\
\hline $\begin{array}{l}\text { Новгородская } \\
\text { область }\end{array}$ & 0,680 & 0,622 & 0,589 & 0,366 & 0,639 & 0,544 & 0,672 & 0,509 & 0,555 & 0,568 \\
\hline $\begin{array}{l}\text { Псковская } \\
\text { область }\end{array}$ & 0,635 & 0,516 & 0,416 & 0,317 & 0,708 & 0,417 & 0,534 & 0,553 & 0,524 & 0,563 \\
\hline $\begin{array}{l}\text { г. Санкт- } \\
\text { Петербург }\end{array}$ & 0,786 & 0,719 & 0,826 & 0,296 & 0,541 & 0,599 & 0,813 & 0,756 & 0,924 & 0,550 \\
\hline $\begin{array}{l}\text { Республика } \\
\text { Адыгея }\end{array}$ & 0,681 & 0,428 & 0,435 & 0,463 & 0,546 & 0,473 & 0,541 & 0,582 & 0,440 & 0,582 \\
\hline
\end{tabular}


Продолжение табл. 3

\begin{tabular}{|c|c|c|c|c|c|c|c|c|c|c|}
\hline $\begin{array}{l}\text { Республика } \\
\text { Калмыкия }\end{array}$ & 0,443 & 0,077 & 0,487 & 0,491 & 0,551 & 0,344 & 0,659 & 0,499 & 0,390 & 0,559 \\
\hline $\begin{array}{l}\text { Краснодарский } \\
\text { край }\end{array}$ & 0,754 & 0,620 & 0,573 & 0,495 & 0,690 & 0,551 & 0,677 & 0,533 & 0,613 & 0,513 \\
\hline $\begin{array}{l}\text { Астраханская } \\
\text { область }\end{array}$ & 0,527 & 0,535 & 0,461 & 0,824 & 0,641 & 0,537 & 0,678 & 0,541 & 0,565 & 0,381 \\
\hline $\begin{array}{l}\text { Волгоградская } \\
\text { область }\end{array}$ & 0,642 & 0,531 & 0,488 & 0,577 & 0,608 & 0,513 & 0,670 & 0,555 & 0,610 & 0,586 \\
\hline $\begin{array}{l}\text { Ростовская } \\
\text { область }\end{array}$ & 0,715 & 0,619 & 0,639 & 0,492 & 0,733 & 0,485 & 0,670 & 0,527 & 0,585 & 0,607 \\
\hline $\begin{array}{l}\text { Республика } \\
\text { Дагестан }\end{array}$ & 0,504 & 0,318 & 0,376 & 0,432 & 0,654 & 0,367 & 0,545 & 0,624 & 0,205 & 0,709 \\
\hline $\begin{array}{l}\text { Республика } \\
\text { Ингушетия }\end{array}$ & 0,371 & 0,276 & 0,299 & 0,533 & 0,207 & 0,196 & 0,536 & 0,491 & 0,007 & 0,586 \\
\hline $\begin{array}{l}\text { Кабардино- } \\
\text { Балкарская } \\
\text { Республика }\end{array}$ & 0,601 & 0,361 & 0,482 & 0,260 & 0,617 & 0,442 & 0,533 & 0,500 & 0,367 & 0,615 \\
\hline $\begin{array}{l}\text { Карачаево- } \\
\text { Черкесская } \\
\text { Республика }\end{array}$ & 0,432 & 0,451 & 0,428 & 0,497 & 0,670 & 0,309 & 0,531 & 0,479 & 0,264 & 0,593 \\
\hline $\begin{array}{l}\text { Республика } \\
\text { Северная Oce- } \\
\text { тия - Алания }\end{array}$ & 0,218 & 0,393 & 0,482 & 0,304 & 0,712 & 0,338 & 0,658 & 0,642 & 0,269 & 0,682 \\
\hline $\begin{array}{l}\text { Чеченская } \\
\text { Республика }\end{array}$ & 0,541 & 0,250 & 0,369 & 0,529 & 0,710 & 0,387 & 0,520 & 0,390 & 0,268 & 0,550 \\
\hline $\begin{array}{l}\text { Ставропольский } \\
\text { край }\end{array}$ & 0,676 & 0,506 & 0,537 & 0,423 & 0,665 & 0,492 & 0,546 & 0,577 & 0,606 & 0,580 \\
\hline $\begin{array}{l}\text { Республика } \\
\text { Башкортостан }\end{array}$ & 0,674 & 0,554 & 0,588 & 0,684 & 0,704 & 0,417 & 0,670 & 0,572 & 0,606 & 0,509 \\
\hline $\begin{array}{l}\text { Республика } \\
\text { Марий Эл }\end{array}$ & 0,603 & 0,504 & 0,475 & 0,214 & 0,694 & 0,308 & 0,547 & 0,472 & 0,536 & 0,487 \\
\hline $\begin{array}{l}\text { Республика } \\
\text { Мордовия }\end{array}$ & 0,671 & 0,485 & 0,594 & 0,072 & 0,643 & 0,441 & 0,665 & 0,669 & 0,602 & 0,617 \\
\hline $\begin{array}{l}\text { Республика } \\
\text { Татарстан }\end{array}$ & 0,792 & 0,673 & 0,711 & 0,795 & 0,686 & 0,579 & 0,787 & 0,748 & 0,781 & 0,532 \\
\hline $\begin{array}{l}\text { Удмуртская } \\
\text { Республика }\end{array}$ & 0,641 & 0,485 & 0,578 & 0,768 & 0,771 & 0,461 & 0,679 & 0,504 & 0,617 & 0,528 \\
\hline $\begin{array}{l}\text { Чувашская } \\
\text { Республика }\end{array}$ & 0,724 & 0,458 & 0,562 & 0,177 & 0,754 & 0,397 & 0,548 & 0,589 & 0,656 & 0,550 \\
\hline Пермский край & 0,637 & 0,600 & 0,667 & 0,749 & 0,746 & 0,536 & 0,675 & 0,572 & 0,538 & 0,500 \\
\hline $\begin{array}{l}\text { Кировская } \\
\text { область }\end{array}$ & 0,684 & 0,547 & 0,522 & 0,275 & 0,738 & 0,432 & 0,662 & 0,558 & 0,757 & 0,526 \\
\hline $\begin{array}{l}\text { Нижегородская } \\
\text { область }\end{array}$ & 0,695 & 0,599 & 0,762 & 0,160 & 0,726 & 0,521 & 0,673 & 0,471 & 0,780 & 0,516 \\
\hline
\end{tabular}


Кузнецова Н. В., Кочева Е. В., Матев Н. А. Методика оценки социально-экономических рисков для ответа России на большие вызовы

Продолжение табл. 3

\begin{tabular}{|c|c|c|c|c|c|c|c|c|c|c|}
\hline $\begin{array}{l}\text { Оренбургская } \\
\text { область }\end{array}$ & 0,585 & 0,555 & 0,452 & 0,852 & 0,711 & 0,480 & 0,679 & 0,760 & 0,594 & 0,493 \\
\hline $\begin{array}{l}\text { Пензенская } \\
\text { область }\end{array}$ & 0,706 & 0,464 & 0,620 & 0,226 & 0,638 & 0,457 & 0,665 & 0,621 & 0,632 & 0,584 \\
\hline $\begin{array}{l}\text { Самарская } \\
\text { область }\end{array}$ & 0,661 & 0,601 & 0,634 & 0,728 & 0,773 & 0,500 & 0,682 & 0,559 & 0,636 & 0,496 \\
\hline $\begin{array}{l}\text { Саратовская } \\
\text { область }\end{array}$ & 0,630 & 0,526 & 0,599 & 0,557 & 0,712 & 0,457 & 0,669 & 0,635 & 0,600 & 0,742 \\
\hline $\begin{array}{l}\text { Ульяновская } \\
\text { область }\end{array}$ & 0,619 & 0,554 & 0,696 & 0,448 & 0,617 & 0,537 & 0,661 & 0,539 & 0,566 & 0,596 \\
\hline $\begin{array}{l}\text { Курганская } \\
\text { область }\end{array}$ & 0,619 & 0,405 & 0,424 & 0,415 & 0,683 & 0,259 & 0,541 & 0,440 & 0,523 & 0,582 \\
\hline $\begin{array}{l}\text { Свердловская } \\
\text { область }\end{array}$ & 0,665 & 0,627 & 0,700 & 0,555 & 0,591 & 0,528 & 0,684 & 0,492 & 0,610 & 0,468 \\
\hline $\begin{array}{l}\text { Тюменская } \\
\text { область }\end{array}$ & 0,641 & 0,726 & 0,591 & 0,974 & 0,707 & 0,760 & 0,790 & 0,520 & 0,727 & 0,294 \\
\hline $\begin{array}{l}\text { Челябинская } \\
\text { область }\end{array}$ & 0,678 & 0,606 & 0,662 & 0,571 & 0,736 & 0,517 & 0,677 & 0,466 & 0,613 & 0,461 \\
\hline $\begin{array}{l}\text { Республика } \\
\text { Алтай }\end{array}$ & 0,668 & 0,423 & 0,366 & 0,516 & 0,762 & 0,429 & 0,543 & 0,520 & 0,362 & 0,746 \\
\hline $\begin{array}{l}\text { Республика } \\
\text { Бурятия }\end{array}$ & 0,669 & 0,524 & 0,543 & 0,653 & 0,740 & 0,468 & 0,537 & 0,491 & 0,425 & 0,577 \\
\hline $\begin{array}{l}\text { Республика } \\
\text { Тыва }\end{array}$ & 0,560 & 0,243 & 0,366 & 0,762 & 0,669 & 0,416 & 0,511 & 0,361 & 0,286 & 0,601 \\
\hline $\begin{array}{l}\text { Республика } \\
\text { Хакасия }\end{array}$ & 0,644 & 0,655 & 0,407 & 0,733 & 0,718 & 0,324 & 0,661 & 0,464 & 0,596 & 0,506 \\
\hline Алтайский край & 0,705 & 0,489 & 0,449 & 0,416 & 0,806 & 0,400 & 0,536 & 0,523 & 0,537 & 0,677 \\
\hline $\begin{array}{l}\text { Забайкальский } \\
\text { край }\end{array}$ & 0,644 & 0,538 & 0,356 & 0,777 & 0,624 & 0,518 & 0,534 & 0,504 & 0,425 & 0,559 \\
\hline $\begin{array}{l}\text { Красноярский } \\
\text { край }\end{array}$ & 0,708 & 0,627 & 0,629 & 0,789 & 0,673 & 0,631 & 0,690 & 0,492 & 0,644 & 0,393 \\
\hline $\begin{array}{l}\text { Иркутская } \\
\text { область }\end{array}$ & 0,672 & 0,641 & 0,566 & 0,820 & 0,679 & 0,569 & 0,675 & 0,485 & 0,531 & 0,417 \\
\hline $\begin{array}{l}\text { Кемеровская } \\
\text { область }\end{array}$ & 0,651 & 0,656 & 0,442 & 0,896 & 0,723 & 0,568 & 0,661 & 0,522 & 0,519 & 0,394 \\
\hline $\begin{array}{l}\text { Новосибирская } \\
\text { область }\end{array}$ & 0,679 & 0,587 & 0,737 & 0,554 & 0,671 & 0,469 & 0,684 & 0,758 & 0,566 & 0,607 \\
\hline Омская область & 0,715 & 0,487 & 0,609 & 0,273 & 0,712 & 0,367 & 0,680 & 0,564 & 0,658 & 0,553 \\
\hline Томская область & 0,704 & 0,496 & 0,834 & 0,795 & 0,649 & 0,484 & 0,695 & 0,752 & 0,587 & 0,481 \\
\hline $\begin{array}{l}\text { Республика Саха } \\
\text { (Якутия) }\end{array}$ & 0,689 & 0,638 & 0,524 & 0,918 & 0,602 & 0,724 & 0,780 & 0,419 & 0,563 & 0,493 \\
\hline $\begin{array}{l}\text { Камчатский } \\
\text { край }\end{array}$ & 0,730 & 0,617 & 0,594 & 0,629 & 0,827 & 0,526 & 0,659 & 0,521 & 0,670 & 0,456 \\
\hline $\begin{array}{l}\text { Приморский } \\
\text { край }\end{array}$ & 0,653 & 0,662 & 0,557 & 0,519 & 0,723 & 0,518 & 0,661 & 0,542 & 0,681 & 0,512 \\
\hline
\end{tabular}




\begin{tabular}{|c|c|c|c|c|c|c|c|c|c|c|}
\hline & & & & & & & & \multicolumn{3}{|c|}{ Окончание табл. 3} \\
\hline $\begin{array}{l}\text { Хабаровский } \\
\text { край }\end{array}$ & 0,690 & 0,608 & 0,668 & 0,678 & 0,741 & 0,525 & 0,668 & 0,473 & 0,649 & 0,513 \\
\hline $\begin{array}{l}\text { Амурская } \\
\text { область }\end{array}$ & 0,668 & 0,530 & 0,434 & 0,755 & 0,765 & 0,693 & 0,546 & 0,610 & 0,624 & 0,495 \\
\hline $\begin{array}{l}\text { Магаданская } \\
\text { область }\end{array}$ & 0,641 & 0,613 & 0,569 & 0,879 & 0,681 & 0,611 & 0,697 & 0,522 & 0,671 & 0,452 \\
\hline $\begin{array}{l}\text { Сахалинская } \\
\text { область }\end{array}$ & 0,575 & 0,800 & 0,501 & 0,892 & 0,787 & 0,847 & 0,691 & 0,519 & 0,671 & 0,440 \\
\hline $\begin{array}{l}\text { Еврейская авто- } \\
\text { номная область }\end{array}$ & 0,624 & 0,551 & 0,373 & 0,632 & 0,767 & 0,511 & 0,521 & 0,355 & 0,549 & 0,512 \\
\hline $\begin{array}{l}\text { Чукотский авто- } \\
\text { номный округ }\end{array}$ & 0,639 & 0,660 & 0,260 & 0,891 & 0,571 & 0,680 & 0,669 & 0,497 & 0,808 & 0,450 \\
\hline $\begin{array}{l}\text { Цветовое обо- } \\
\text { значение }\end{array}$ & \multicolumn{5}{|c|}{$\begin{array}{l}\text { Значение интегрального } \\
\text { показателя }\end{array}$} & \multicolumn{5}{|c|}{ Характеристика } \\
\hline & \multicolumn{5}{|c|}{$0,000-0,399$} & \multicolumn{5}{|c|}{ Критический риск } \\
\hline & \multicolumn{5}{|c|}{$0,400-0,499$} & \multicolumn{5}{|c|}{ Высокий риск } \\
\hline & \multicolumn{5}{|c|}{$0,500-0,599$} & \multicolumn{5}{|c|}{ Допустимый риск } \\
\hline & \multicolumn{5}{|c|}{$0,600-0,699$} & \multicolumn{5}{|c|}{ Умеренный риск } \\
\hline & \multicolumn{5}{|c|}{$0,700-0,799$} & \multicolumn{5}{|c|}{ Низкий риск } \\
\hline & \multicolumn{5}{|c|}{$0,800-1,000$} & \multicolumn{5}{|c|}{ Очень низкий риск } \\
\hline
\end{tabular}

Несмотря на очевидные имеющиеся преимущества России в контексте ответа на «большие вызовы», стоящие перед нашей страной, в настоящее время мы сталкиваемся с кругом вопросов и задач, которые требуют немедленного решения. В недавно принятой Стратегии научно-технологического развития Российской Федерации не находит отражение весь спектр проблем, с которым сталкивается наше государство в процессе социально-экономического роста [16]. Всё ещё требуют внимания демографические проблемы, проблемы высокой дифференциации населения по уровню и качеству жизни в субъектах страны, проблемы конкурентоспособности регионов России в научно-технологической, социальной, образовательной областях и здравоохранении, а также неэффективная сырьевая направленность экономики, высокая степень износа основных фондов и использование устаревших технологий. Таким образом, перед Россией и её субъектами стоят важные задачи, решение которых позволит сформировать эффективную программу развития, способствующую ответить нашей стране на «большие вызовы».

Вызов. Новая волна технологических изменений. Подъём конкурентоспособности страны на мировых высокотехнологичных рынках.

В контексте задач, направленных на технологическое развитие Российской Федерации, возникает риск снижения конкурентоспособности страны на мировых технологичных рынках. Согласно нашим расчётам, большинство субъектов России - 
Кузнецова Н. В., Кочева Е. В., Матев Н. А. Методика оценки социально-экономических рисков для ответа России на большие вызовы

61,3\% сконцентрировались в группе с умеренным риском снижения конкурентоспособности. В данной группе субъектов по итогам 2017 г. значения показателей, входящих в оценочную категорию по данному риску, находились на уровне среднероссийских значений. Удельный вес организаций, осуществляющих технологические инновации, находился в пределах 6\% в общем числе организаций. При этом доля инновационных товаров, работ и услуг в общем объёме не превышала в среднем 7\%. По объёмам промышленного производства и объёмам выпущенной продукции организациями с участием иностранного капитала лидирующие позиции в данной группе субъектов РФ занимали Чукотский автономный округ, Магаданская область, Республика Саха (Якутия) и Тюменская область.

В группу с низким риском конкурентоспособности по итогам 2017 г. вошли 18 субъектов России, что составило 22,5\% общего числа субъектов. Данную группу составили преимущественно крупные субъекты Центрального, Северо-Западного, Южного и Сибирского федеральных округов. Здесь наблюдались высокие показатели объёмов промышленного производства, объёмов выпущенной продукции с участием иностранного капитала, весьма низкая в сравнении с другими субъектами России степень износа основных фондов. Доля организаций, осуществляющих технологические инновации, в общем объёме в субъектах данной группы варьировалась в пределах от $7 \%$ до $20 \%$.

В критическую зону субъектов с высокими рисками снижения конкурентоспособности вошли Республики Ингушетия, Северная Осетия - Алания (группа критического риска), Калмыкия и Карачаево-Черкесская Республика (группа высокого риска). В данных субъектах наблюдались самые низкие значения рассматриваемых показателей, характеризующих конкурентоспособность региона.

Большинство субъектов Дальневосточного федерального округа по степени риска конкурентоспособности вошли в состав группы субъектов с умеренным риском, за исключением Сахалинской области (зона субъектов с допустимым риском, преимущественно за счёт низкой доли выпущенной инновационной продукции и высокой степени износа основных фондов). Камчатский край по итогам 2017 г. вошёл в группу субъектов с низким риском конкурентоспособности.

Вызов. Преодоление консервативности внешнеэкономической деятельности. Догнать страны лидеры по продвижению продукции на мировые рынки.

Как видно из таблицы 3, 70\% субъектов Российской Федерации вошли в группы с допустимыми и умеренными рисками потери потенциала взаимных торговых потоков. В зону субъектов с низким и очень низким риском потери потенциала торговых потоков вошли пять субъектов России: города Москва и СанктПетербург, Калининградская, Тюменская и Сахалинская области. Это обусловлено тем, что внешнеторговые связи центральных субъектов со странами базируются, преимущественно, по таким направлениям, как сотрудничество в развитии сферы 
высоких технологий и научно-технического потенциала, образовании, здравоохранении. Внешнеторговые отношения Тюменской и Сахалинской области базируются преимущественно на высоком ресурсно-сырьевом потенциале этих субъектов, здесь также на протяжении рассматриваемого периода наблюдаются самые высокие показатели экспорта ресурсов в России.

В группу субъектов России с критическим риском потери потенциала торговых потоков вошли преимущественно субъекты Северо-Кавказского федерального округа. Это объясняется тем, что рынок экспорта и импорта в регионе является закрытым, поскольку внешнеэкономическая квота (отношение суммы экспорта и импорта к ВРП) составила около $6 \%$.

К группе с высоким риском потери потенциала торговых потоков относятся 12 субъектов России (15\% общего числа). Здесь преимущественно сосредоточились аграрно-ориентированные экономики России, где также наблюдаются весьма низкие внешнеторговые квоты.

В целом, говоря о потенциале торговых потоков в России, стоит отметить, что основу российского экспорта составляют нефть, газ и металлы, которые, в свою очередь, являются ключевой продукцией для ресурсно-сырьевых экономик с низкой добавленной стоимостью. Поэтому весьма неудивительно, что четверть субъектов Российской Федерации находятся в группе с высокими рисками потери потенциала торговых потоков и дальнейшей интеграции в отраслевые товарные рынки.

Вызов. Необходимость преодоления технологического разрыва

В зону низкого и очень низкого риска отставания научно-технологического потенциала и снижения инновационной активности экономики вошли 10 субъектов Российской Федерации (7 и 3 , соответственно) - 12,5\% общего числа субъектов. В их числе города федерального значения - Москва и Санкт-Петербург - ведущие научные и образовательные центры России, обладающие элементами инновационной инфраструктуры, рядом конкурентоспособных отраслей, инновационнотехнологическими центрами и являющиеся особыми экономическими зонами технико-внедренческого типа; Томская область, на территории которой расположены инновационный территориальный кластер «Фармацевтика, медицинская техника и информационные технологии» и инновационно-промышленный кластер возобновляемых ресурсов; и следующие за ними: Нижегородская область с мощным оборонно-промышленным комплексом, включающим предприятия авиа- и судостроения, высокоточного приборостроения, атомной энергетики, радиоэлектроники и других наукоёмких, высокотехнологичных производств; Новосибирская область с уникальным научно-образовательным потенциалом, на территории которой размещён крупнейший центр академической и прикладной науки в азиатской части нашей страны и другие не менее интересные субъекты России в контексте инновационного развития. 
Кузнецова Н. В., Кочева Е. В., Матев Н. А. Методика оценки социально-экономических рисков для ответа России на большие вызовы

Однако, несмотря на весьма внушительный потенциал научно-технического и инновационного развития в одних субъектах Российской Федерации, другие субъекты (36\%), к сожалению, находятся в зонах критического и высокого риска отставания научно-технического потенциала и снижения инновационной активности. К субъектам кризисной зоны относятся, преимущественно, субъекты СевероКавказского, Южного и Центрального федеральных округов. Из субъектов Дальневосточного федерального округа в числе кризисных зон оказались Еврейская автономная область и Чукотский автономный округ.

Вызов. Исчерпание потенциала экспортно-сырьевой модели экономического развития России

По результатам расчёта значений риска сырьевой отсталости видно, что в зону с низкими рисками вошли субъекты Российской Федерации с ресурсносырьевой направленностью экономики - это субъекты Дальневосточного, СевероЗападного, Сибирского и Уральского федеральных округов. Данные регионы весьма богаты природными ресурсами, а экономика большинства их субъектов базируется на добыче полезных ископаемых.

Большинство субъектов Российской Федерации (63\%) вошли в состав групп субъектов с критическим, высоким и допустимым риском сырьевой отсталости ввиду отсутствия подобных масштабов промышленного производства полезных ископаемых - к данным субъектам относятся субъекты европейской части России.

В качестве ещё одного риска в рамках данного вызова, стоящего перед Россией, является риск сужения производства товаров массового потребления, в первую очередь продовольствия.

В группу с низкими и умеренными рисками сужения производства товаров массового потребления, в первую очередь продовольствия, попали в большинстве своём аграрные субъекты Российской Федерации. В данной группе сосредоточены субъекты, в которых наблюдаются весьма высокие объёмы реализации пищевых продуктов организациями торговли и общественного питания, доля расходов населения на продовольствие в общих расходах варьируется в пределах 30-35\%.

В группу субъектов с высокими рисками вошли Республика Ингушетия, за счёт высокой доли расходов населения на продовольствие и высокий индекс потребительских цен на продовольственные товары.

\section{Вызов. Развитие макротехнологических производств}

Согласно данным таблицы 3 , в группу субъектов с критическим и высоким рисками снижения инвестиционной привлекательности вошли 38 субъектов России, что составляет 47,5\% общего числа. В данных группах субъектов отмечаются низкие объёмы инвестиций в основной капитал в расчёте на душу населения и невысокие объёмы поступления иностранных инвестиций по сравнению со среднероссийским уровнем. 
В группу субъектов с низкими рисками снижения инвестиционной привлекательности вошли 5 субъектов, в числе которых сырьевые Тюменская область и Республика Саха (Якутия), а также города федерального значения Москва и СанктПетербург.

\section{Вызов. Формирование качественного экономического роста}

Рассматриваемый вызов характеризуется четырьмя рисками - деградации человеческого потенциала, снижения качества жизни населения, напряжённости на рынке труда и загрязнения окружающей среды.

Из рассчитанных данных видно, что в зону критического и высокого риска деградации человеческого потенциала не вошёл ни один субъект Российской Федерации. Большинство субъектов (65\%) вошли в зону умеренного риска деградации человеческого потенциала. Безусловными лидерами по уровню развития человеческого потенциала являются города Москва и Санкт-Петербург, Республика Саха (Якутия), Республика Татарстан, а также Тюменская область, риск деградации человеческого потенциала в которых минимальный.

Что касается риска снижения качества жизни населения, то можно отметить, что в зону низкого риска вошли 9 субъектов России, что составляет 11,3\% общего числа. Большинство субъектов страны сконцентрированы в зонах допустимого и высокого рисков снижения качества жизни населения. Заметим, что в эти две группы вошло большинство субъектов Дальнего Востока, за исключением Еврейской автономной области (зона критического риска) и Амурской области (зона умеренного риска).

В кризисную зону риска напряжённости на рынке труда попали преимущественно субъекты Северо-Кавказского федерального округа. Большинство субъектов сконцентрированы в зонах допустимого и умеренного риска $(33,8 \%$ и $38,7 \%$ соответственно), в том числе субъекты Дальневосточного федерального округа.

В настоящее время трудовые ресурсы являются важнейшим фактором социально-экономического развития России и её регионов. В результате преобразований форм и методов хозяйствования происходит трансформация структуры современного рынка труда и воспроизводства рабочей силы. В условиях формирования инновационной экономики требуются новые подходы к оценке качества трудового потенциала, поскольку от этого зависит формирование предложения на рынке труда, как в стране, так и её регионах.

Последний риск в рамках данного вызова - риск загрязнения окружающей среды. Согласно расчётам по итогам 2017 г., подавляющее большинство субъектов России находилось в группе допустимого риска загрязнения окружающей среды (38 субъектов, что составило 47,5\% общего числа). В зону низкого риска вошли три субъекта страны - Республики Дагестан и Алтай, а также Саратовская область.

В рамках настоящего исследования была приведена многопараметрическая оценка социально-экономических рисков в субъектах страны с целью определения кризисных 
Кузнецова Н. В., Кочева Е. В., Матев Н. А. Методика оценки социально-экономических рисков для ответа России на большие вызовы

территорий, которые имеют определённые проблемы, связанные с возникающими и имеющимися большими вызовами. Таким образом, для определения приоритетных направлений развития экономики в субъектах Российской Федерации целесообразным является определение факторов, влияющих на экономический рост регионов.

Дальневосточный регион имеет важное геополитическое и геостратегическое значение для России. Выгодное географическое положение Дальневосточного округа, его близость к странам Азиатско-Тихоокеанского региона, а также наличие богатых природных ресурсов, транспортной инфраструктуры позволяют осуществлять транзитные функции между странами АТР, западными странами и Европой, что способствует развитию международной торговли. На Дальнем Востоке России реализуются долговременные специфические геостратегические цели государства обеспечение военно-политического и экономического влияния в бассейне Тихого океана, контроль над важнейшими стратегическими запасами сырьевых ресурсов. Экономическое развитие Дальнего Востока должно обеспечить поддержание и упрочнение статуса России как мировой державы на Тихом океане.

В настоящее время со стороны государства уделяется повышенное внимание инвестиционному развитию Дальневосточного округа. С 2015 г. во Владивостоке ежегодно проводится Восточный экономический форум с целью формирования новых экономических режимов и улучшения инвестиционного климата, социальной инфраструктуры и развития регионов Дальнего Востока России. По итогам 2019 г., как отметил в своём выступлении заместитель председателя правительства - полпред президента в Дальневосточном федеральном округе Ю. П. Трутнев, на Дальнем Востоке принято более 40 законов, направленных на стимулирование инвестиционной активности и улучшение социальной сферы, создано 20 территорий опережающего развития, 5 свободных портов, реализовано свыше 1780 инвестиционных проектов и создано более 230 новых предприятий. Однако, несмотря на положительные тенденции, всё ещё требуют решения вопросы социально-экономического развития дальневосточных территорий, поиска эффективных международных форм взаимодействия Дальнего Востока России и стран АТР, которые позволят участникам достичь синергетического эффекта в использовании компетенций стран-партнёров как ответ на «большие вызовы».

Для реализации задачи определения приоритетных направлений развития субъектов Дальневосточного федерального округа в контексте рассмотренных больших вызовов и рисков невозможности им противостоять предлагается построение логистической регрессии, где в качестве зависимой переменной будут выступать темпы роста валового регионального продукта в субъектах, а в качестве предикторов - исходный набор показателей для оценки социально-экономических рисков, представленный в таблице 1. Зависимая переменная является дихотомической, то есть дамми-переменной, принимающей значение по следующей схеме: 
-0 - если в субъекте в отчётном периоде по сравнению с предыдущим темп роста валового регионального продукта был меньше $100 \%$;

-1- если в субъекте в отчётном периоде по сравнению с предыдущим темп роста валового регионального продукта был больше, либо равен 100\%.

Итоги построения логит-регрессии для субъектов Дальневосточного федерального округа представлены в табл. 4.

Таблицуа 4

\section{Итоги построения логит-регрессии}

для субъектов Дальневосточного федерального округа

\begin{tabular}{|l|l|l|}
\hline \multicolumn{1}{|c|}{ Variables in the Equation } & \multicolumn{1}{c|}{ B } & \multicolumn{1}{c|}{-value } \\
\hline Intercept & $-1,0340$ & 0,0623 \\
\hline$R C$ & 0,0305 & 0,0897 \\
\hline STUD & 0,0093 & 0,0716 \\
\hline$U N$ & $-0,2335$ & 0,0336 \\
\hline$G V A$ & 0,0348 & 0,0789 \\
\hline$M I$ & 0,0091 & 0,0197 \\
\hline$A E$ & $-3,6220$ & 0,0478 \\
\hline & Statistics \\
\hline$N$ & 72 & \\
\hline Chi-square & 68,427 \\
\hline Nagelkerke $R$ square & 0,759 \\
\hline Overal Persentage & 80,62 \\
\hline AIK & 87,78 \\
\hline
\end{tabular}

Результаты логистической модели, представленной в табл. 4, показывают, что на темпы экономического роста в субъектах Дальнего Востока России значимое положительное влияние оказывают факторы: душевые затраты на научные исследования и разработки; численность студентов высших учебных заведений; доля валовой добавленной стоимости добывающих производств в общем объёме; миграционный прирост. Увеличение данных показателей позволит снизить риск отставания научно-технического потенциала и снижения инновационной активности экономики ДВФО, а также минимизировать риск сырьевой отсталости.

Отдельного внимания заслуживает показатель коэффициента миграционного прироста населения. На протяжении всего рассматриваемого периода практически во всех субъектах Дальневосточного федерального округа наблюдается миграционный отток населения. В целом за период 1990-2017 гг. численность населения региона сократилась с 8064 млн чел. до 6165 млн чел. (на 23,55\%) под воздействием есте- 
Кузнецова Н. В., Кочева Е. В., Матев Н. А. Методика оценки социально-экономических рисков для ответа России на большие вызовы

ственной и механической убыли населения. Люди покидают Дальний Восток в силу влияния таких факторов, как суровые природно-климатические условия, слабая урбанизированность и неразвитость городских центров, низкое качество жизни населения (по сравнению с другими субъектами центральной части России). Большую часть мигрантов составляют люди с высшим образованием, которые покидают регион с целью реализации своего человеческого капитала, увеличения уровня и качества жизни. Поэтому в Дальневосточном регионе государству необходимо разрабатывать и реализовывать комплексные программы по стимулированию населения, в особенности молодёжи, не покидать регион. Одной из попыток государства по привлечению населения в Дальневосточной федеральный округ является программа «Дальневосточный гектар», которая начала свою реализацию в 2015-2016 гг., однако на текущий момент времени демографические проблемы региона решить не удалось. Таким образом, решение проблемы миграционного оттока из субъектов Дальнего Востока позволит сократить риск деградации человеческого потенциала, что скажется, в свою очередь, и на качестве экономического роста.

Отрицательное воздействие на темпы экономического роста в субъектах Дальневосточного федерального округа оказывают показатели уровня безработицы и объёмы выбросов загрязняющих веществ в атмосферный воздух. Проблема безработицы населения весьма актуальна для Дальнего Востока. Одной из причин её возникновения является отдалённость поселений от крупных городских центров, отсутствие работы в сёлах. Различия в уровне социально-экономического развития между городом и селом становятся всё более глубокими, что проявляется в устойчивом развитии большинства городов и деградации сельской местности. Сельскохозяйственное производство всегда было основным источником занятости сельчан на Дальнем Востоке, однако вместе с распадом СССР «развалилось» и наше сельское хозяйство. В итоге во многих деревнях и сёлах сейчас нет работы, а если таковая и имеется, то уровень оплаты значительно ниже, чем в городе. Наибольший уровень безработицы по итогам 2017 г. наблюдался в аграрной Еврейской автономной области и Республике Саха (Якутия) - 8,3\% и 7,1\% соответственно.

Что касается отрицательного влияния выбросов загрязняющих веществ в атмосферу, можно отметить, что Дальневосточный федеральный округ занимает предпоследнее место по объёмам выбросов среди прочих федеральных округов России, однако в динамике значение рассматриваемого показателя увеличивается, преимущественно за счёт субъектов с развитой добычей полезных ископаемых.

Таким образом, построенные логистические уравнения регрессии подтверждают, что основным вектором развития экономик субъектов Российской Федерации является необходимость преодоления технологического разрыва и снижения риска отставания научно-технического потенциала и снижения инновационной активности экономики. 


\section{Список литературы}

1. Understanding and tackling societal grand challenges through management research / G. George, J. Howard-Grenville, A. Joshi [et al.] // Academy of Management Journal. - 2016. - Vol. 59, iss. 6. - P. 1880-1895.

2. Climate change and management / J. Howard-Grenville, S. J. Buckle, B. J. Hoskins [et al.] // Academy of Management Journal. - 2014. - Vol. 57, iss. 3. P. 615-623.

3. Aging populations and management / C. T. Kulik, S. Ryan, S. Harper [et al.] // Academy of Management Journal. - 2014. - Vol. 57, iss. 4. - P. 929-935.

4. George, G. The management of natural resources: An overview and research agenda / G. George, S. J. D. Schillebeeckx, T. L. Liak // Academy of Management Journal. - 2015. - Vol. 58, iss. 6. - P. 1595-1613.

5. Hall, P. Policy paradigms, social learning, and the state: the case of economic policymaking in Britain // Comparative Politics. - 1993. - Vol. 25, iss. 3. - P. 275-296.

6. Managing risk and resilience / G. S. van der Vegt, P. Essens, M. Wahlstroem [et al.] // Academy of Management Journal. - 2015. - Vol. 58, iss. 4. - P. 971-980.

7. Grodal, S. How does a grand challenge become displaced? Explaining the duality of field mobilization / S. Grodal, S. O'Mahony // Academy of Management Journal. 2017. - Vol. 60, iss. 5. - P. 1801-1827.

8. Colbert, A. The digital workforce and the workplace of the future / A. Colbert, N. Yee, G. George // Academy of Management Journal. - 2015. - Vol. 59, iss. 3. - P. 731-739.

9. Managing digital money / M. Dodgson, D. Gann, I. Wladawsky-Berger [et al.] // Academy of Management Journal. - 2015. - Vol. 58, iss. 2. - P. 325-333.

10. Gender research in AMJ: An overview of five decades of research and call to action / A. Joshi, B. Neely, C. Emrich [et al.] // Academy of Management Journal. 2015. - Vol. 58, iss. 5. - P. 1459-1475.

11. Churchman, C. W. Wicket problems // Management Science. - 1967. Vol. 14. - P. 141-142.

12. Rittel, H. Dilemmas in a general theory of planning / H. W. J. Rittel, M. M. Webber // Policy Sciences. - 1973. - Vol. 4, iss. 2. - P. 155-169.

13. Клочков, В. В. Парадигма «больших вызовов» в системе стратегического планирования научно-технологического развития // Россия: тенденции и перспективы развития. - 2017. - № 12 (3). - С. 389-395.

14. Grand Challenges Canada. Grand Défis Canada. Bold ideas for humanity. The Grand Challenges Approach. 2011. - URL: https://www.grandchallenges.ca/wpcontent/uploads/2017/11/thegrandchallengesapproach.pdf (дата обращения: 22.12.2019).

15. Кузнецова, Н. В. Парадигма «больших вызовов» - новый этап развития мировой экономической системы // Менеджмент в России и за рубежом. - 2018. № 6. - C. 4-15. 
Кузнецова Н. В., Кочева Е. В., Матев Н. А. Методика оценки социально-экономических рисков для ответа России на большие вызовы

16. Стратегия научно-технологического развития Российской Федерации : указ Президента Российской Федерации от 1 декабря 2016 г. № 642. - URL: http://kremlin.ru/acts/bank/41449 (дата обращения: 22.12.2019).

\section{References}

1. George G., Howard-Grenville J., Joshi A. et al. Understanding and tackling societal grand challenges through management research. Academy of Management Journal, 2016, vol. 59, iss. 6, pp. 1880-1895.

2. Howard-Grenville J, Buckle S.J., Hoskins B.J. et al. Climate change and management. Academy of Management Journal, 2014, vol. 57, iss. 3, pp. 615-623.

3. Kulik C.T., Ryan S., Harper S. et al. Aging populations and management. Academy of Management Journal, 2014, vol. 57, iss. 4, pp. 929-935.

4. George G., Schillebeeckx S.J.D., Liak T.L. The management of natural resources: An overview and research agenda. Academy of Management Journal, 2015, vol. 58, iss. 6, pp. 1595-1613.

5. Hall P. Policy paradigms, social learning, and the state: the case of economic policymaking in Britain. Comparative Politics, 1993, vol. 25, iss. 3, pp. 275-296.

6. Van der Vegt G.S., Essens P., Wahlstroem M. et al. Managing risk and resilience. Academy of Management Journal, 2015, vol. 58, iss. 4, pp. 971-980.

7. Grodal, S., O'Mahony S. How does a grand challenge become displaced? Explaining the duality of field mobilization. Academy of Management Journal, 2017, vol. 60, iss. 5, pp. 1801-1827.

8. Colbert A., Yee N., George G. The digital workforce and the workplace of the future. Academy of Management Journal, 2015, vol. 59, iss. 3, pp. 731-739.

9. Dodgson M., Gann D., Wladawsky-Berger I. et al. Managing digital money. Academy of Management Journal, 2015, vol. 58, iss. 2, pp. 325-333.

10. Joshi A., Neely B., Emrich C. et al. Gender research in AMJ: An overview of five decades of research and call to action. Academy of Management Journal, 2015, vol. 58, iss. 5, pp. 1459-1475.

11. Churchman C.W. Wicket problems. Management Science, 1967, vol. 14, pp. 141-142.

12. Rittel H.W.J., Webber M.M. Dilemmas in a general theory of planning. Policy Sciences, 1973, vol. 4, iss. 2, pp. 155-169.

13. Klochkov V.V. Paradigma «bol'shikh vyzovov» v sisteme strategicheskogo planirovaniya nauchno-tekhnologicheskogo razvitiya [The paradigm of «big challenges» in the strategic planning system of scientific and technological development]. Rossiya: tendentsii i perspektivy razvitiya, 2017, no. 12 (3), pp. 389-395.

14. Grand Challenges Canada. Grand Défis Canada. Bold ideas for humanity. The Grand Challenges Approach. 2011. Available at: https://www.grandchall 
enges.ca/wp-content/uploads/2017/11/thegrandchallengesapproach.pdf (accessed 22 December 2019).

15. Kuznetsova N.V. Paradigma «bol'shikh vyzovov» - novyi etap razvitiya mirovoi ekonomicheskoi sistemy [The paradigm of «big challenges»-a new stage in the development of the global economic system]. Menedzhment $v$ Rossii i za rubezhom, 2018, no. 6 , pp. $4-15$.

16. The strategy of scientific and technological development of the Russian Federation: Decree of the President of the Russian Federation dated December 1, 2016 No. 642. Available at: http://kremlin.ru/acts/bank/41449 (accessed 22 December 2019). (In Russian). 